\title{
Digital fibromas. Report of three cases
}

\section{Patricia Chang, Tyson Meaux, Gylari Calderón Pacheco}

\author{
Department of Dermatology, Hospital General de Enfermedades IGSS and Hospital Ángeles, Guatemala
}

Corresponding author: Dr. Patricia Chang, E-mail: pchang2622@gmail.com

\begin{abstract}
Digital fibroma is a rare benign lesion that usually occurs during the first 2 years of life. It can be multiple, but it is usually a single lesion. If it grows large enough it can cause joint deformities or interfere with everyday activities. We report 3 cases of digital fibroma 2 in female patient and 1 in male patient due to its uncommon localization of fibromas.
\end{abstract}

Key words: Digital fibroma; fibromatosis; tumor

\section{INTRODUCTION}

Digital fibromas may be found in children or adults, and consist of solitary or multiple papules or nodules on the fingers or toes. Histologically, they consist of benign-appearing spindle cells devoid of cytologic atypia [1]. Infantile digital fibromatosis is a variant in young children, and is a rare benign fibroproliferative tumor of early childhood that typically spontaneously involutes in 2 to 3 years [2]. There is also a cellular variant that has dense CD $34+$ spindle cells and may mimic dermatofibrosarcoma protuberans (DFSP) histologically. It important to correctly diagnose this variant of digital fibroma, considering the implications of an incorrect diagnosis of DFSP [3]. While typically a relatively small tumor, an acquired tumor has been reported grow quite large, with measurements of $2.5 \times 1.6 \times 1.4 \mathrm{~cm}$, appropriately named in that report as "giant acquired digital fibroma" [4]. The cause of acquired digital fibromas is unknown; however, similar to plantar fibromas, they may be secondary to trauma [5]. In addition, there has been report of acquired digital fibrokeratoma caused by cyclosporine [6]. It is important to keep a wide differential diagnosis when a patient presents with a lesion on the digits.

\section{CASE REPORT}

\section{Case 1}

86 year old female hospitalized with pneumonia, found to have a skin lesion on her left foot, on the plantar surface of the great toe. It was a $5 \mathrm{~cm}$ smooth, pedunculated, skin-colored neoplasm (Fig. 1). Dermoscopy revealed the skin colored neoplasm with the previously described characteristics (Fig. 2). Rest of the physical exam was within normal limits.

The patient did not remember when the lesion first appeared, did not pay much attention to it, and noted that it was asymptomatic.

\section{Case 2}

86 year old male hospitalized in the Male Medicine Service for an upper GI hemorrhage, noted to have a skin lesion on the lateral surface of digit on right foot, characterized by a $4 \mathrm{~cm}$ pigmented neoplasm (Fig. 3 ). Rest of physical exam: dry skin, onychogryphosis of bilateral great toes. He reported that the lesion appeared roughly 1 year ago, has been asymptomatic, and has not received treatment for it. 


\section{Case 3}

58 year old female, hospitalized for poorly controlled diabetes mellitus, noted to have a neoplasm to plantar surface of great toe of right foot. Closer examination revealed a $8 \mathrm{~cm}$ skin colored, wide-based, flat neoplasm (Fig. 4). Patient noted that the lesion had been there for 2 years, and it occasionally caused mild pain, but she had never received treatment for it. Biopsy of the lesion was performed, with report of neoformation covered by a acanthotic epidermis and consists of a little collagen fiber defined symmetrical proliferation, grouped in bundles which are arranged in different directions (Fig. 5), A 40x, thick collagen fibers with moderate fibroblasts, some of triangular appearance are observed. In addition there is proliferation of blood vessels (Fig. 6).

All three patients were diagnosed with digital fibromas, and all three were seen coincidentally during their hospital stay for treatment of a systemic disease. It is important to emphasize the importance of a good

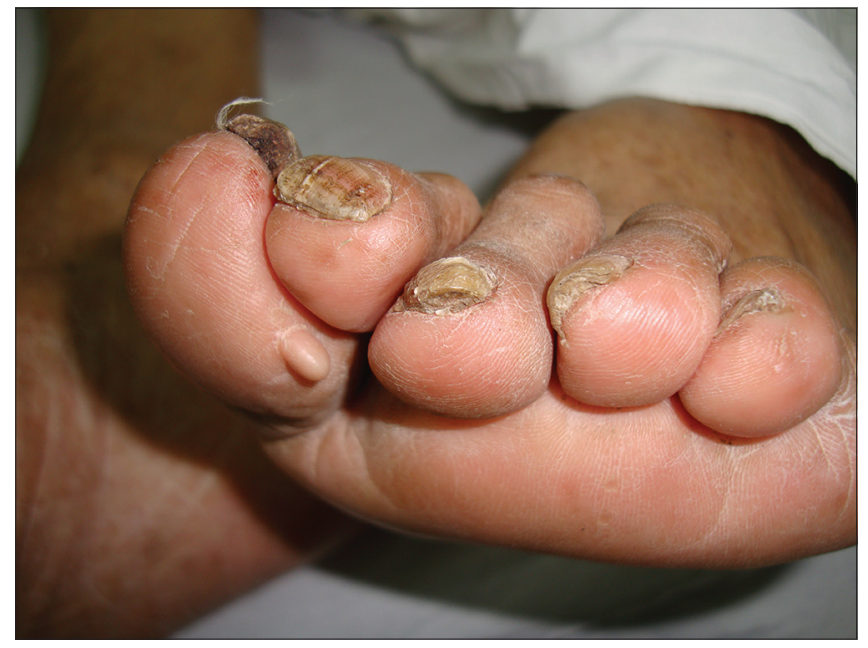

Figure 1: Tumor on left plantar bigtoenail.

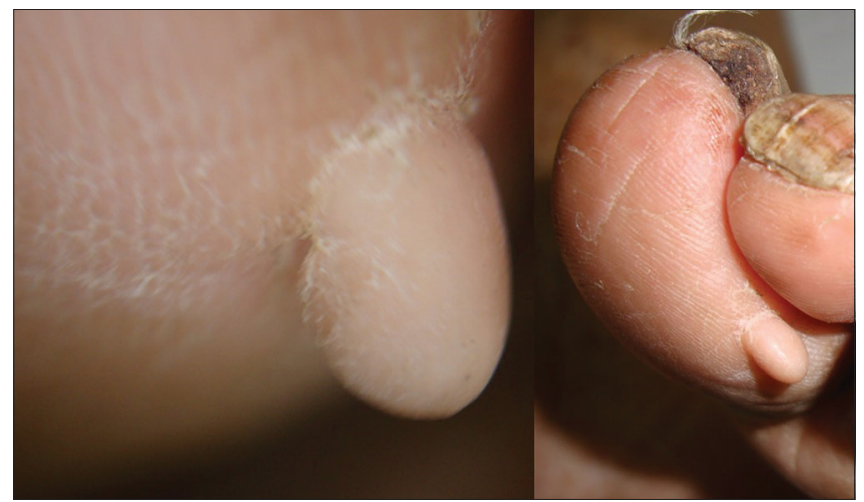

Figure 2: Dermatoscopic view of the tumor. physical exam, including the skin, to avoid missing a skin lesion, be it benign or malignant.

\section{DISCUSSION}

These are prototypical cases of digital fibroma, however it is important to keep in mind that benign and malignant tumors can occur in the toes, including aggressive digital papillary adenocarcinoma mimicking acquired digital fibrokeratoma, and metatastic tumors from the viscera. Consider biopsying any new or recurrent mass, and any digital lesions not responding to treatment $[7,8]$. Histology differs based on the type of digital fibroma. Koenen tumors, which are periungual fibromas found in tuberous sclerosis, often originate from the proximal nail fold and show capillaries in the distal part surrounded by thin collagen bundles while the proximal part consists of dense, closely packed fibers $[9,10]$. Histology of

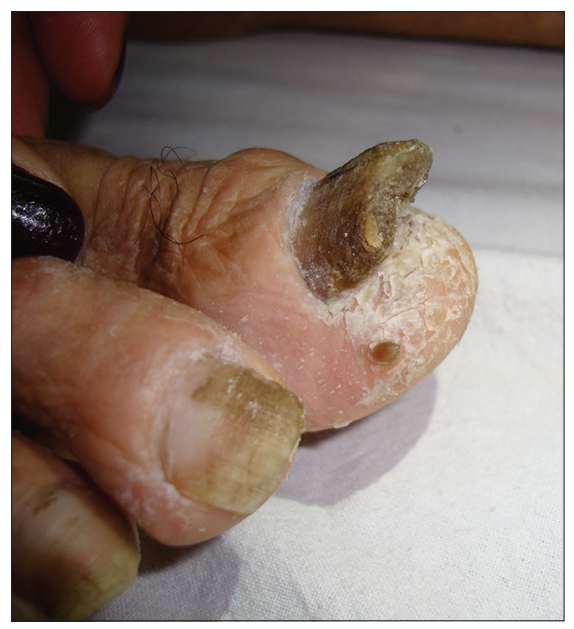

Figure 3: Tumor on the right plantar bigtoenail.

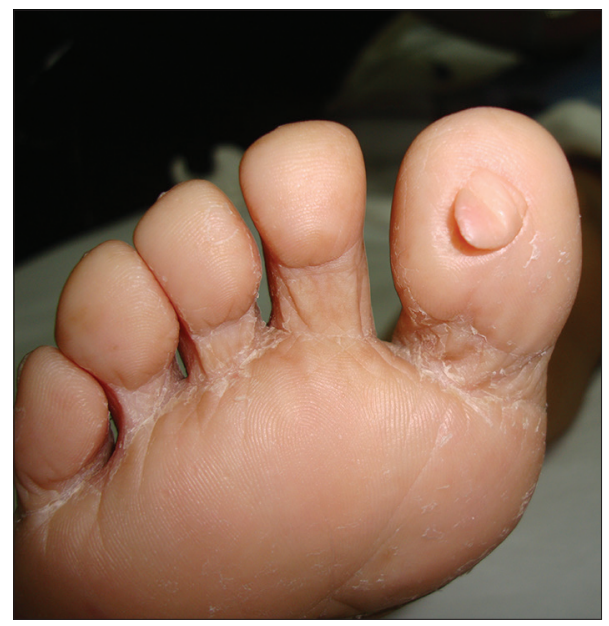

Figure 4: Big soft tumor on the digit. 


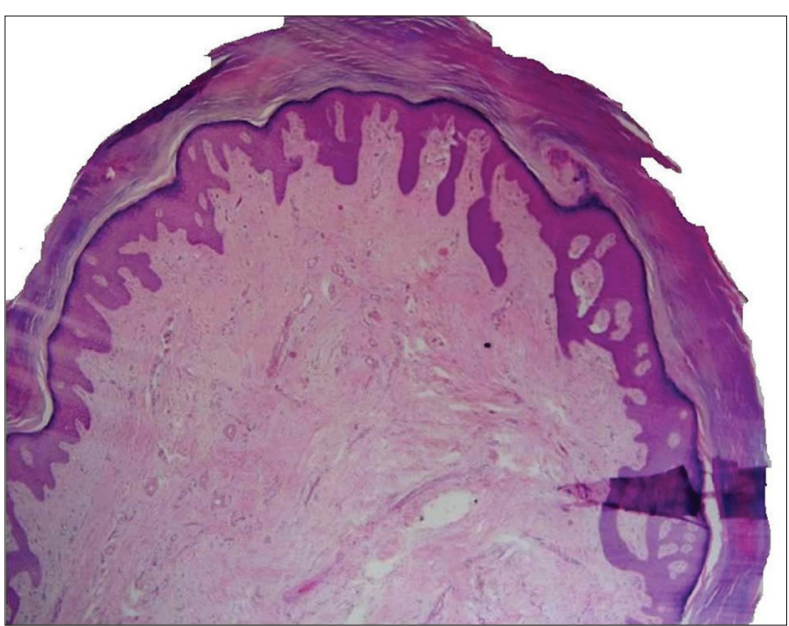

Figure 5: Neoformation covered by a acanthotic epidermis and consists of a little collagen fiber defined symmetrical proliferation, grouped in bundles which are arranged in different directions. (H\&E 40x)

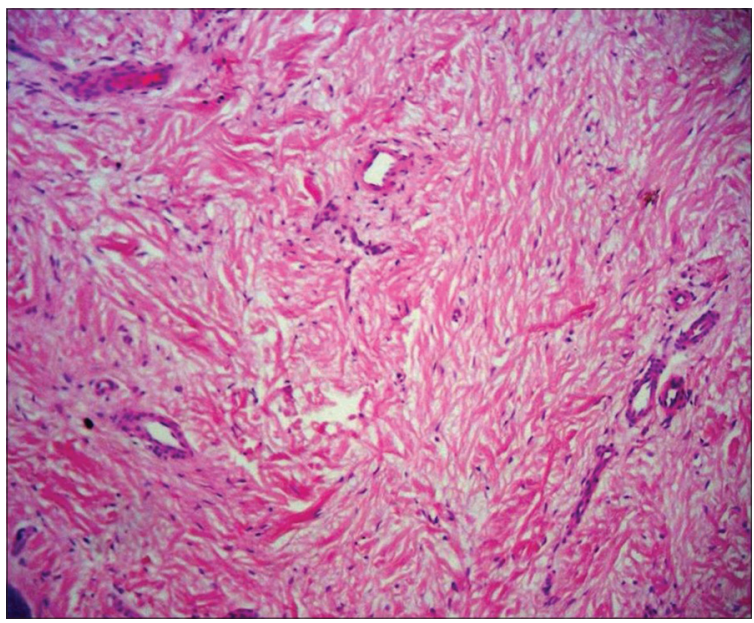

Figure 6: A thick collagen fibers with moderate fibroblasts, some of triangular appearance are observed. In addition, there is proliferation of blood vessels. (H\&E 40x)

recurrent digital fibroma of childhood shows round, eosinophilic cytoplasmic inclusion bodies, which are myofibroblastic in nature [11]. Interestingly, myofibrolastic features identical to those found in recurring digital fibroma of childhood were found in four patients involved in the toxic oil epidemic syndrome (TOES) in Spain in 1981, which caused generalized sclerodermoid skin changes [12]. As mentioned previously, treatment for infantile digital fibromatosis is typically observation, with spontaneous involution in 2-3 years as the rule. Identification of this entity is important to prevent an unnecessary surgical procedure [2]. Once other more dangerous conditions such as those previously mentioned have been excluded in acquired cases, shave excision under local anesthesia is appropriate management for digital fibromas [13].

\section{REFERENCES}

1. Plaza JA, Suster S, Prieto VG, Sangueza M. Acquired reactive digital fibroma: a clinicopathologic report of 5 cases of a new entity. J Am Acad Dermatol. 2013 Oct; 69(4):603-8.

2. Valérie F, Odile W, Nikkels-Tassoudji N, Carlier A, Josette A, Nikkels, A. Congenital infantile digital fibromatosis: a case report and review of the literature. Rare Tumors. 2009 Dec 28; 1(2).

3. McNiff JM, Subtil A, Cowper SE, Lazova R, Glusac EJ. Cellular digital fibromas: distinctive CD34-positive lesions that may mimic dermatofibrosarcoma protuberans. J Cutan Pathol. 2005 Jul; 32(6):413-8.

4. Choi J, Jung S, Chun J, Seo J, Lee D, Hwang S, Sung H. Giant Acquired Digital Fibrokeratoma Occurring on the Left Great Toe. Ann Dermatol. 2011 Feb; 23(1): 64-66.

5. Bakotic, B. W. Tumors of the Soft Tissue of the Lower Extremity In: Levy, L. A., Hetherington, V., \& Bakotic, B. W. (2006). Principles and practice of podiatric medicine. Brooklandville, $\mathrm{Md}$ : Data Trace Pub. Co. Chap 17:17-7.

6. Qiao J, Liu YH, Fang K. Acquired digital fibrokeratoma associated with ciclosporin treatment. Clin Exp Dermatol. 2009 Mar. 34(2):257-9.

7. Chi CC, Kuo TT, Wang SH. Aggressive digital papillary adenocarcinoma: a silent malignancy masquerading as acquired digital fibrokeratoma. Am J Clin Dermatol. 2007. 8(4):243-5.

8. Potter G. Neoplasia in the toes and toenail areas. Clin Podiatr Med Surg. 1995 Apr; 12(2):287-97.

9. Kint A, Baran R. Histopathologic study of Koenen tumors. Are they different from acquired digital fibrokeratoma? J Am Acad Dermatol. 1988 Feb; 18(2 Pt 1):369-72.

10. de Berker D, Higgins C, Jahoda C, Christiano A. Nail Disorders In: Bolognia JL, Jorizzo JL, Schaffer JV, eds. Dermatology. $3^{\text {rd }}$ ed. Philadelphia, PA: Elsevier Saunders; 2012:chap 71:1144.

11. Mortimer G, Gibson A. Recurring digital fibroma. J Clin Pathol. 1982 Aug; 35(8): 849-854.

12. Navas-Palacios JJ, Conde-Zurita JM. Inclusion body myofibroblasts other than those seen in recurring digital fibroma of childhood. Ultrastruct Pathol. 1984;7(2-3):109-21.

13. Vinson R, Angeloni V. Acquired digital fibrokeratoma. Am Fam Physician. 1995 Oct; 52(5):1365-7.

Copyright by Patricia Chang, et al. This is an open-access article distributed under the terms of the Creative Commons Attribution License, which permits unrestricted use, distribution, and reproduction in any medium, provided the original author and source are credited.

Source of Support: Nil, Conflict of Interest: None declared. 